\title{
LIMITES DAS RESTRIÇÓES AOS DIREITOS FUNDAMENTAIS EM TEMPOS DE CRISE, ORÇAMENTO PÚBLICO E O PERIGO DA JURISDIÇÃO CONSTITUCIONAL DE EXCEÇÃO
}

\author{
LIMITS OF RESTRICTIONS ON FUNDAMENTAL RIGHTS IN TIMES OF \\ CRISIS, PUBLIC BUDGET AND THE DANGER OF CONSTITUCIONAL \\ EXCEPTIONAL JURISDICTION
}

\author{
Jadson Correia de Oliveira ${ }^{\mathrm{I}}$ iD \\ Luiz Augusto Agle Fernandez Filho ${ }^{\mathrm{II}}$
}

\footnotetext{
${ }^{\mathrm{I}}$ Universidade Federal de Sergipe, São Cristóvão, SE, Brasil. Doutor em Direito. E-mail: jadson_correia@hotmail. com

${ }^{\text {II }}$ Universidade Católica do Salvador, Salvador, BA, Brasil. Pós-Graduado em Direito Tributário e Direito Processual Civil. E-mail: luizaugustoagle@gmail. com
}

Resumo: O presente artigo tem por finalidade identificar a existência de um núcleo essencial de Direitos Fundamentais, que mesmo em tempos de crise devem ser respeitados e promovidos, bem como os limites da atuação do Poder Judiciário nessa missão. Para tanto, inicialmente serão analisadas as balizas constitucionais do estado de exceçáo, tomando-se como exemplo a atual pandemia, decorrente do novo coronavírus (Sars-CoV-2), que, como se verá, não pode servir como uma cortina de fumaça para a flexibilização irrestrita das normas da Constituição, nem como escusa para o retrocesso e violação dos direitos e garantias fundamentais. Em seguida, serão abordados os principais princípios constitucionais que fundamentam o direito à prestação mínima do Estado e às liberdades individuais dos cidadáos, sopesando-se as dificuldades orçamentárias para a promoçáo desses Direitos, no cenário de crise econômica, decorrente do combate à calamidade pública. Ao final, serão analisados os princípios dos direitos fundamentais e a cláusula pétrea da separação dos Poderes, em face da ordem democrática e as limitaçóes da jurisdição constitucional no enfretamento das crises institucionais. A análise será por meio de pesquisa bibliográfica e normativa, e o princípio da proporcionalidade se demonstrará como um importante instrumento, a nível de compatibilizar os direitos (fundamentais) individuais e coletivos com a ordem constitucional democrática.

Palavras-chave: Estado de exceção. Direitos Fundamentais. Restriçôes. Jurisdição constitucional.

Abstract: The purpose of this article is to identify the existence of an essential nucleus of Fundamental Rights that, even in times of crisis, must be respected and promoted, as well as the limits of the Judiciary's role in this mission. To this end, initially the constitutional beacons of the state of exception 
will be analyzed, taking as an example the current pandemic resulting from the new coronavirus (Sars-CoV-2), which, as will be seen, cannot serve as a smoke screen for flexibility unconstrained by the norms of the Constitution, nor as an excuse for the retrogression and violation of fundamental rights and guarantees. Then, the main constitutional principles that underlie the right to the minimum provision of the State and the individual freedoms of citizens will be addressed, considering the budgetary difficulties for the promotion of these Rights, in the scenario of economic crisis, resulting from the fight against public calamity. In the end, the principles of fundamental rights will be analyzed, as well as the stony clause of the separation of Powers, in view of the democratic order and the limitations of constitutional jurisdiction in facing institutional crises. The analysis will be through bibliographic and normative research, and the principle of proportionality will be demonstrated as an important instrument, in terms of making individual and collective (fundamental) rights compatible, with the democratic constitutional order.

Keywords: Exception State. Fundamental rights. Restrictions. Constitutional jurisdiction.

\section{Introdução}

Om o agravamento da crise sanitária, decorrente do alastramento do novo
coronavírus (Sars-CoV-2), o Brasil reconheceu o Estado de Calamidade Pública, mediante o Decreto Legislativo no 6, de 20 de março de $2020^{1}$.

O Estado de Calamidade, uma vez decretado, revela-se como um instrumento válido para que a Administração Pública possa realizar medidas, excepcionais e provisórias, a fim de combater a pandemia. Porém, as referidas açóes devem se pautar pela ordem constitucional, com respeito ao Estado de Direito, notadamente aos direitos e garantias fundamentais.

Pois, em sentido amplo, um estado de exceção, fruto de uma situação anormal de risco social, impacta na ordem privada e pública, tanto individual quanto coletivamente, afetando as relaçôes jurídicas (sociais e econômicas), bem como o funcionamento regular das instituiçóes.

Nesse contexto, a presente pesquisa se volta à análise jurídico-constitucional dos direitos fundamentais e aos limites de suas restriçóes para o enfrentamento de graves crises, a exemplo da decorrente propagaçáo do referido vírus. Considerando que o constituinte originário, ao prever os requisitos formais e materiais para o enfretamento das crises, através do estado de defesa e de sítio, traçou os limites que devem ser respeitados pelo Estado, em casos, inclusive, mais graves ao do atual, estado de calamidade pública.

Em face do primado da saúde pública, diversos entes federados vêm justificando medidas, cada vez mais restritivas das liberdades individuais dos cidadãos. Porém, impende observar quais são os limites dessas restriçôes, de modo a identificar a existência de intervençóes

1 BRASIL. Congresso Nacional. Decreto Legislativo no 6, de 20 de março de 2020. Brasília, DF. Disponível em: http://www.planalto.gov.br/ccivil_03/portaria/DLG6-2020.htm. Acesso em: 09 mai, 2020. 
estatais inconstitucionais, bem como verificar a ocorrência de omissóes ilegítimas para a garantia de direitos mínimos aos indivíduos em tempos de grave crise sanitária, social e econômica, eis que vedada a prestação estatal insuficiente.

O ponto nevrálgico do presente artigo, encontra-se na análise jurídico-constitucional dos limites da possibilidade de restrição dos direitos fundamentais em situaçóes de grave anormalidade, sem que a crise instaurada sirva, apenas, de instrumento legitimador de intervençóes e omissóes inconstitucionais, voltadas para interesses outros que náo o de retorno imediato da normalidade do Estado de Direito. Pois, sob o manto da decretação de um estado de exceção, não deve se autorizar a prática de qualquer ato em detrimento da ordem democrática e do conteúdo mínimo dos direitos fundamentais.

Destaca-se que para o combate das referidas situaçóes excepcionais, é autorizada a flexibilização dos limites orçamentários (artigo 65 da Lei de Responsabilidade Fiscal), a fim de viabilizar a utilização de recursos para a realização das políticas públicas voltadas ao enfrentamento da situação de emergência. Além disso, o Estado pode se valer dos mecanismos extraordinários de arrecadação para incrementar o financiamento público, a exemplo do empréstimo compulsório e da instituição de um imposto extraordinário.

Nesse cenário, destaca-se a importância dos órgãos de controle interno e externo, na fiscalização tanto do orçamento público em face das dispensas de licitação e da execução de contratos, quanto a jurisdiçáo constitucional, em face do cenário de incerteza, que pode dar azo a graves violaçôes de direitos fundamentais assegurados pela Constituição.

Nesse contexto, enfrentar-se-á a questáo relacionada ao orçamento público e ao custo dos direitos fundamentais, de forma a conferir melhor compreensão das questóes relacionadas às competências constitucionais dos Poderes da República e o paradoxo da democracia ${ }^{2}$.

Assim, busca-se identificar os contornos mínimos, que devem ser observados e respeitados, referentes aos princípios que asseguram os direitos fundamentais, mesmo em situaçóes excepcionais, inerentes ao estado de crise. Com efeito, será analisado o papel dos Poderes da República para a conformação da ordem constitucional vigente, respeitando-se o primado da democracia, através da cláusula pétrea da Separação dos Poderes.

Para tanto, no presente trabalho, será analisado o núcleo instransponível dos Direitos Fundamentais, com base no princípio da proporcionalidade, em prol da efetividade das garantias que foram estabelecidas pelo constituinte originário. No entanto, a grande questão levantada na presente pesquisa se refere aos limites do Poder Judiciário no exercício da sua competência constitucional para efetivar essa missão ${ }^{3}$, sem que a sua atuação sirva como escusa para a usurpação de competência dos demais Poderes.

\section{Sistema constitucional de combate às crises institucionais}

A proteção das instituições democráticas e a promoção do equilíbrio da ordem constitucional, em situaçóes excepcionais, são asseguradas mediante o sistema constitucional de

2 ALEXY, Robert. Teoria dos direitos fundamentais. Trad. de Virgílio Afonso da Silva. São Paulo: Malheiros, 2008, p. 447.

3 WANG. Daniel Wei Liang. Escassez de recursos, custos dos direitos e reserva do possível na jurisprudência do STF. Revista Direito GV, São Paulo. p. 539-568. jul-dez 2008. 
crises. Fundado pelos princípios da necessidade e da temporariedade, este sistema de defesa visa à estabilização do sistema constitucional, em caso de processos violentos ou de perturbação da estabilidade constitucional ${ }^{4}$.

Por sua vez, em face de situaçóes gravíssimas, antevendo as consequências, o constituinte originário optou por regulamentá-las, pela eventualidade da sua ocorrência. Para tanto, a própria Carta Magna estipula uma releitura de diversos dispositivos constitucionais e, com isso, se tem uma "legalidade de exceção" norteadora do estado de exceçãos.

Com efeito, permite-se ao Estado o uso de ferramentas excepcionais e temporárias, para o enfretamento de graves crises, com o desiderato de promover o reestabelecimento da situação de normalidade, tendo o constituinte ponderado diretamente, no texto constitucional, a possibilidade de restrição de direitos individuais e coletivos em prol da preservação da nação.

O "Sistema Constitucional das Crises" composto pelos denominados Estado de Defesa (artigo 136 da CRFB/88), e Estado de Sítio (artigos 137 a 139 da CRFB/88), em conjunto com a Intervenção Federal (artigos 34 a 36 da CRFB/88), são medidas excepcionalíssimas, dispostas na Constituição, para o reestabelecimento da ordem e preservação do Estado em face de circunstâncias graves necessárias ao seu reconhecimento ${ }^{6}$.

Além dessas medidas, no plano infraconstitucional o legislador previu, para fins de flexibilização orçamentária, o Estado de Calamidade Pública no art. 65 da Lei de Responsabilidade Fiscal, que conforme visto, fora recentemente decretado no Brasil ${ }^{7}$, com o fito de facilitar o combate à pandemia desencadeada pela disseminaçáo do novo coronavírus.

Todos os dispositivos mencionados se referem a mecanismos excepcionais para o combate à situaçóes de emergência e crise, mas antes de adentar nas nuances dos seus institutos, cumpre analisar as características do estado de exceção.

\section{Estado de Exceção ${ }^{8}$}

Em contraponto à noção de Estado de Direito tem-se a de Estado de Exceção, atribuindose ao cientista político Carl Schmitt o desenvolvimento dos contornos essenciais do instituto, nas obras Die Diktatur (A ditadura) e Politisehe Theologie (Teologia Política) respectivamente de 1921 e $1922^{9}$.

4 SANTOS. Aricê Moacyr Amaral. O Estado de Emergência. São Paulo: Sugestôes Literárias, 1981, p. 32-33.

5 SILVA, José Afonso da. Curso de Direito Constitucional Positivo. 25. Edição. Malheiros: São Paulo, 2005, p. 766.

6 Ibid., p. 760.

7 O Brasil destaca-se negativamente no cenário mundial, por conta dos elevados índices de contaminação e mortes, conforme divulgado pela John Hopkins University, Disponível em: https:/www.arcgis.com/apps/ opsdashboard/index.html\#/bda7594740fd40299423467b48e9ecf6. Acesso em: 30 jun. 2020.

8 Consoante Giorgio Agamben: "Esse termo, comum na doutrina alemã (Ausnahmezustand, mas também Notstand, estado de necessidade), e estranho as doutrinas italiana e francesa, que preferem falar de decretos de urgência e de estado de sítio (político ou ficticio, etat de siege fictif). Na doutrina anglo-saxônica, prevalecem, porém, os termos martial law e emergency powers". (AGAMBEN, Giorgio. Estado de Exceção. Tradução Iraci Poleti. 2 ed. São Paulo: Boitempo, 2004, p.15).

9 Segundo Giorgio Agamben: "O aporte específico da teoria schmittiana é exatamente de tornar possível tal articulação entre o estado de exceção e a ordem jurídica. Trata-se de uma articulação paradoxal, pois o que deve ser inscrito no direito é algo essencialmente exterior a ele, isto é, nada menos que a suspensão da própria ordem jurídica (donde a formulação aporética: "Em sentido jurídico (...), ainda existe uma ordem, mesmo não sendo 
O Estado de Exceção é um fenômeno complexo, pois se situa entre a Política e o Direito. É pensado em diversas tradiçôes jurídicas como parte do direito positivo ${ }^{10}$, por ser considerado uma fonte autônoma de direito, no entanto para outros juristas seria um direito subjetivo (natural) ${ }^{11}$ do Estado a sua própria conservação. Noutro giro, parte da doutrina considera um fenômeno extrajurídico ${ }^{12}$, sito no campo essencialmente da política, fundado pela necessidade, ainda que possa gerar consequências no âmbito do Direito ${ }^{13}$.

A ideia de Estado de Exceção está atrelada à suspensão, total ou parcial, do ordenamento jurídico, em face de uma situação temporária e urgente, que revele absoluta necessidade. Diante de tais circunstâncias excepcionais, o Estado teria mecanismos de autotutela, voltados a reestabelecer o status quo de normalidade, ao custo da excepcionalização dos direitos e obrigações, pois "necessitas legem non habet" (a necessidade não tem lei).

Segundo Giorgio Agamben, na lição schmittiana, o Estado de Exceção, constitucionalmente previsto, equivaleria a uma "ditadura constitucional", que se diferenciaria de uma "ditadura do soberano", na medida em que a suspensão da "ordem jurídica" da primeira ("ditadura comissária”), ocorreria para defender a existência da própria Constituição e, portanto, revelaria o mínimo de "Direito", enquanto a segunda seria em detrimento da própria Carta Magna, a fim de promover uma ruptura constitucional ${ }^{14}$.

No entanto, o Estado de Exceção deve ser tratado sempre com muita cautela, devendo ser cabível, somente, em situaçóes excepcionalíssimas e de acordo com as balizas materiais e formais previstas na Constituição, pois, como observa Carl Friedrich, a concentração excepcional de poderes, em determinadas circunstâncias, pode levar a um regime totalitário, e a esse respeito adverte que: "Não há nenhuma salvaguarda institucional capaz de garantir que os poderes de emergência sejam efetivamente usados com o objetivo de salvar a constituição" ${ }^{15}$.

Por conta disso, passa-se a análise dos requisitos traçados pelo constituinte brasileiro de 1988, para a instituição do regime excepcional de combate às crises institucionais.

\subsection{Balizas constitucionais: Estado de Sitio}

Algumas restriçóes aos direitos fundamentais emanam diretamente do texto da Constituição, mormente subjacentes à regulamentação excepcional de "estado de necessidade", compreendidos o estado de defesa e o de sítio ${ }^{16}$.

A Constituição Federal prevê os requisitos formais e materiais para a decretação do estado de sítio e do de defesa, bem como da intervençáo federal, sendo que os dois primeiros interessam ao objeto do presente estudo.

uma ordem jurídica”)". (AGAMBEN, Giorgio. Estado de Exceção. Tradução Iraci Poleti. 2 ed. São Paulo: Boitempo, 2004, p.55).

10 Ex: Santi Romano, Hauriou e Mortati.

11 Ex: Hoerni, Ranellerri e Rossiter.

12 Ex: Biscarerri, Balladore-Pallieri e Carre de Malberg.

13 AGAMBEN, Giorgio. Op. Cit., p.39.

14 Ibid., p.55.

15 FRIEDRICH, Carl Joachim. Constitutional Government and Democracy. 2. ed. rev. Boston, Ginn, 1950. (I. ed. 1941), p. 828.

16 MENDES, Gilmar Ferreira; BRANCO, Paulo Gustavo Gonet; Curso de direito constitucional. 7a ed. São Paulo: Saraiva. 2012, p. 297. 
Em comum, destaca-se que ambos os institutos são marcados pela transitoriedade, possibilidade de abertura de crédito extraordinário mediante medida provisória (artigo 167, $\$ 3^{\circ} \mathrm{CRFB} / 88^{17}$ ), além de limitarem o poder constituinte derivado, ante a impossibilidade de elaboração de emendas constitucionais (artigo 60, $\$ 1^{\circ} \mathrm{CRFB} / 88$ ).

O Estado de Exceção deve ser provisório, sob o risco de se converter em um regime totalitarista. Para tanto, o constituinte originário se preocupou em fixar prazos de vigência e condições para a prorrogação, excetuado o caso de guerra, que pode perdurar pelo tempo de duração da ameaça armada estrangeira.

Assim, pela ordem de excepcionalidade, cumpre tratar do caso de maior gravidade e aptidão para restrição dos direitos fundamentais, qual seja, o estado de sítio, que, somente tem espaço nos casos de "comoção grave de repercussão nacional ou ocorrência de fatos que comprovem a ineficácia de medida tomada durante o estado de defesa/ declaraçáo de estado de guerra ou resposta à agressão armada estrangeira" (pressupostos materiais).

Da leitura da materialidade do cabimento do estado de sítio extrai-se a sua natureza subsidiária, das demais modalidades de combate as crises. Tendo espaço na primeira hipótese, apenas, como ultima ratio, quando as outras medidas adotadas pelo Estado se revelarem, comprovadamente, ineficazes.

No aspecto formal subjetivo, a competência da decretação é exclusiva do Presidente da República (Chefe do Poder Executivo), necessitando da prévia oitiva dos Conselhos da República e de Defesa Nacional, cujo parecer tem natureza meramente opinativa, porém a medida deve ser submetida a controle prévio do Congresso Nacional, cabendo, portanto, ao Poder Legislativo autorizar ou não a implementação do estado de sítio (pressupostos formais).

O artigo 139 da CRFB/88, dispóe que:

$\mathrm{Na}$ vigência do estado de sítio decretado com fundamento no art. 137, I, só poderão ser tomadas contra as pessoas as seguintes medidas: I - obrigação de permanência em localidade determinada; II - detenção em edifício não destinado a acusados ou condenados por crimes comuns; III - restrições relativas à inviolabilidade da correspondência, ao sigilo das comunicaçôes, à prestação de informaçôes e à liberdade de imprensa, radiodifusão e televisão, na forma da lei; IV - suspensão da liberdade de reunião; V - busca e apreensão em domicílio; VI - intervenção nas empresas de serviços públicos; VII - requisição de bens. ${ }^{18}$

Portanto, tratam-se de restrições a direitos fundamentais, expressamente previstas no texto constitucional.

\subsection{Estado de defesa}

Por outro lado, o estado de defesa corresponde a uma modalidade menos drástica de Estado de Exceção constitucionalmente autorizado. Destina-se, por tempo determinado, após Decreto do Presidente da República, ouvidos os Conselhos da República e de Defesa Nacional, a

17 Como exemplo, em 25 de março de 2020, foi editada a Medida Provisória n ${ }^{\circ}$ 929/20 para abrir crédito extraordinário de pouco mais de $\mathrm{R} \$ 3,4$ bilhôes, para o enfrentamento da emergência de saúde pública decorrente da Covid-19. Disponível em: http://www.planalto.gov.br/ccivil_03/_Ato2019-2022/2020/Mpv/ mpv929.htm. Acesso em: 16 jun, 2020.

18 BRASIL. Constituição da República Federativa do Brasil, de 1988. Brasília, DF. Disponível em: http://www. planalto.gov.br/ccivil_03/Constituicao/Constituicao.htm. Acesso em: 09 mai, 2020. 
preservar ou prontamente restabelecer, em locais restritos e determinados (pressupostos formais), a ordem pública ou a paz social ameaçada por grave e iminente instabilidade institucional ou atingidas por calamidades de grandes proporçôes na natureza (pressupostos materiais). Neste caso, poderão ser estabelecidas restriçôes excepcionais aos direitos de: a) reuniáo, b) sigilo de correspondência e c) comunicação telegráfica e telefônica (vide artigo 136, $\left.\$ 1^{\circ}, \mathrm{I}, a-c \mathrm{CRFB} / 88\right)^{19}$.

Portanto, os estados de sítio e de defesa relativizam a aplicação de determinadas normas jurídicas, restringindo direitos e definindo os requisitos para o seu exercício, a fim de promover a preservação do equilíbrio constitucional e da estabilidade das instituiçôes democráticas.

Náo obstante no ano de 2020 ter sido reconhecido no Brasil o Estado de Calamidade Pública, apenas, para os fins do artigo 65 da Lei Complementar $n^{\circ} 101 / 2000$, cujo prazo findou em 31/12/2020, e embora o Supremo Tribunal Federal tenha prorrogado a vigência da Lei $13.979 / 2020^{20}$ antes mesmo da votaçáo do projeto que tramita no Congresso nacional, impende atentar-se acerca da constitucionalidade das restriçôes dos direitos fundamentais promovidas pelas autoridades públicas, em todas as esferas de governo, para o enfrentamento da crise desencadeada pelo Sars-CoV-2.

Pois, conforme visto, o "estado de necessidade" não justifica qualquer violação de direito, apesar de excepcionalmente flexibilizar a aplicação de determinadas garantias, desde que estritamente necessárias à restauração da normalidade.

No entanto, a ordem jurídica constitucional traça os limites desse mecanismo, motivo pelo qual se enfrentará mais adiante a constitucionalidade da Lei n. ${ }^{\circ}$ 13.979/2020 e das medidas adotas pelos Estados e Municípios no exercício de suas competências suplementares, que impuseram graves e rigorosas medidas restritivas de direitos fundamentais, sob o fundamento de enfrentar a crise decorrente da pandemia. Mas, antes disso, cumpre enfrentar as questóes relacionadas aos limites e restriçôes dos direitos fundamentais individuais e coletivos, com maior enfoque nos de segunda geração, visto que se trata de objeto central da pesquisa.

\section{Estado de Exceção e a restrição dos direitos fundamentais}

A evolução do Direito Constitucional está relacionada com a "afirmação dos direitos fundamentais como núcleo da proteçâo da dignidade da pessoa e da visão de que a Constituição é o local adequado para positivar as normas asseguradoras dessas pretensôes" ${ }^{21}$. Assim, atrelado ao reconhecimento da constituiçáo na ordem hierárquica máxima do ordenamento, vislumbrouse a necessidade de se constitucionalizar os valores mais importantes à existência do homem, com o fito de assegurar os direitos no tempo.

Interessa ao presente capítulo desta pesquisa, a análise dos direitos reconhecidos como fundamentais em tempos de crise e os limites das suas restriçôes, iniciando-se com os direitos individuais relacionados às liberdades negativas, e em seguida os denominados de segunda

19 BRASIL. Constituição da República Federativa do Brasil, de 1988. Brasília, DF. Disponível em: http://www. planalto.gov.br/ccivil_03/Constituicao/Constituicao.htm. Acesso em: 09 mai, 2020.

20 Norma que dispóe sobre as medidas para enfrentamento da emergência de saúde pública de importância internacional decorrente do coronavírus responsável pelo surto de 2019.

21 MENDES, Gilmar Ferreira; BRANCO, Paulo Gustavo Gonet; Curso de direito constitucional. $7^{\text {a }}$ ed. Sáo Paulo: Saraiva. 2012, p. 203. 
geração, pautados sobre as premissas da liberdade e igualdade material, que se dariam através da atuação positiva do poder público, a fim de alcançar a justiça social e não mais, apenas, a abstenção de intervenção do Estado.

Por fim, serão analisados os limites do Poder Judiciário na interpretação e aplicação da Constituição Federal, dentro da sua posição constitucional entre os Poderes da República, não havendo um "Poder Moderador" das demais funçóes constitucionais.

\subsection{Suporte fático e restriçōes}

A atual crise, decorrente do efeito pandêmico desencadeado pelo novo coronavírus e as suas constantes mutaçóes, colocou o mundo jurídico na situação de ponderar o direito (fundamental) à saúde pública coletiva, com os demais direitos e garantias fundamentais dos indivíduos ${ }^{22}$.

Em Portugal, foi a primeira vez em 43 anos, ou seja, desde a edição da Constituição de 1976, que instaurou-se um Estado de Exceção constitucional, com a promulgação do Estado de Emergência para o enfrentamento da crise de saúde ${ }^{23}$.

$\mathrm{Na}$ experiência portuguesa, sob a égide do Estado de Exceção, motivou-se a edição de medidas concretas de redução dos direitos fundamentais através de diversas normas (especiais), instrumentos de exceção administrativa, a exemplo da Lei do Sistema de Vigilância em Saúde Pública. Diante disso, com a hipertrofia da Administraçáo Pública em geral e, em especial, da centralidade das políticas econômicas-financeiras com o governo, Moniz adverte que "o sistema português confrontou-se com a projeção jurídica dos efeitos de uma pandemia no plano dos direitos fundamentais, enquadrada por uma moldura normativa nem sempre clara”2425.

A fim de analisar a constitucionalidade das ações realizadas pelo Estado brasileiro, nas restriçôes realizadas aos direitos fundamentais, impende, primeiramente, traçar os contornos dos institutos.

Adotando-se a teoria alexyana ${ }^{26}$ dos direitos fundamentais, o âmbito de proteção e o suporte fático não se trata da mesma coisa, dependendo do tipo de norma de direito fundamental

22 Alguns países orientais, embora partilhem de uma dogmática mais restritiva de direitos humanos, como Taiwan, Cingapura e a Região Administrativa Especial de Macau, por terem sofrido as consequências da SARS-CoV no início deste século, entre 2001 e 2004, tiveram uma resposta jurídico-administrativa mais célere, em relação aos países ocidentais, por terem se estruturado para o enfrentamento de um agravamento da crise sanitária, a exemplo da Lei de prevenção, controle e tratamento de doenças transmissíveis da Região Administrativa Especial de Macau editada em 2004, após o surto para evitar uma nova situação epidêmica. In. MONIZ, Ana Raquel Gonçalves. Promoção da saúde pública e proteção dos direitos fundamentais: a COVID-19 à luz das repercussōes jurídico-constitucionais e jurídico-administrativas em Portugal. Cadernos Ibero-Americanos de Direito Sanitário. Brasília, 10(2): abr./jun., 2021, p. 187.

23 Ibid., p. 187.

24 Ibid., p. 188 e 193.

25 Desde 2011, ao eclodir a crise econômica em Portugal, consoante o magistério de Zachia Alan, acentuou-se os argumentos acerca da relativizaçáo dos preceitos preconizadores de direitos e garantias fundamentais, de tal modo, que o autor expressa preocupação e crítica a "validade variável da constituição a depender de turbulência institucional”. Cf. ALAN, José Alexandre Zachia. Crise e justiça constitucional - uma tentativa de paralelo entre Portugal e o Brasil e os questionamentos acerca da validade da constituição, in Revista do Ministério Público do RS, Porto Alegre, n. 76, jan-abr/2015, p. 69.

26 Consoante leciona Robert Alexy: "Uma teoria material dos direitos fundamentais como teoria normativa geral é possível apenas na forma de uma teoria dos princípios. Acima já se demonstrou que princípios e valores são a mesma coisa, de um lado em uma roupagem deontológica e, de outro, em uma roupagem axiológica”. ALEXY, 
que se trate, mas ambos são a contraparte (oposição) do conceito de restrição, por revelarem o que as normas garantem prima facie, sem considerar as possíveis restriçóes - teoria externa de restriçãa ${ }^{27}$.

O suporte fático simplesmente descreve o bem abstratamente protegido pela norma, o que está previsto no tipo normativo, sua hipótese de incidência e o antecedente da norma, mas segundo o autor esta não é uma razão suficiente para uma construção do suporte fático apenas com base no interesse protegido, no caso das açóes negativas ${ }^{28}$.

Para Robert Alexy, enquanto conceito contraposto ao de restrição, o suporte fático deve abranger "todos os pressupostos materiais para a ocorrência da consequência jurídica prima

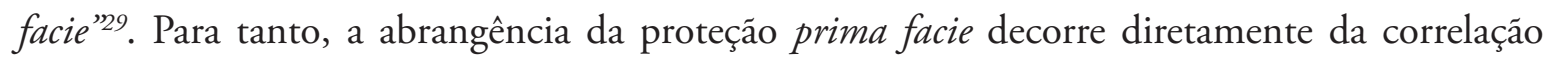
entre a extensão do conceito de bem protegido e de intervenção (inclui no conceito de suporte fático bem protegido e intervenção).

Ainda, segundo Alexy, "O âmbito de proteção em sentido amplo abrange tudo aquilo que é prima facie proibido" 30 . A construção do suporte fático composto pelo bem protegido e pela intervenção baseia-se nas relações entre os conceitos de intervenção, de bem protegido, de restrição, com os de proibição definitiva e prima facie (direito definitivo e prima facie).

Portanto, na lição alexyana, todas as medidas que se caracterizem enquanto intervençôes a um bem protegido, são prima facie proibidas. Logo, as intervenções que não sejam justificadas por uma restrição, são definitivamente proibidas pelo direito fundamental. Mas adverte que uma norma só pode ser uma restrição a um direito fundamental desde que seja compatível material e formalmente com a Constituição.

As reservas legais constitucionais são as normas de competência que autorizam, por excelência, a restrição dos direitos fundamentais, através da atuação do legislador, ou seja, a reserva legal não é a restrição em si, mas a autorização constitucional conferida ao legislador (possibilidade jurídica), potencial e indireta, para que se edite normas que restrinjam direitos fundamentais $^{31}$. Cita como exemplo o Tribunal Constitucional Federal quando afirma que "direitos fundamentais de terceiros e outros valores jurídicos de hierarquia constitucional" também podem restringir direitos fundamentais, ele faz referência a restriçóes a direitos fundamentais que têm caráter de princípios" 32 .

Chama a atenção que alguns casos se tratam de cláusulas restritivas ou de parte do próprio suporte fático de incidência (descrição constitucional da extensão substancial do direito). Portanto, a cláusula restritiva diretamente constitucional decorre de uma opção do constituinte em prol de determinadas razôes contra a proteção constitucional ${ }^{33}$.

Robert. Teoria dos direitos fundamentais. Trad. de Virgílio Afonso da Silva. São Paulo: Malheiros, 2008, p. 561.

27 Ibid., p. 302.

28 ALEXY, Robert. Teoria dos direitos fundamentais. Trad. de Virgílio Afonso da Silva. São Paulo: Malheiros, 2008, p. 303.

29 Ibid., p. 305.

30 Ibid., p. 306.

31 Ibid., p. 280-281.

32 Ibid., p. 284.

33 Ibid., p. 287. 
Com relação às cláusulas diretamente constitucionais na modalidade não escrita, excepcionalmente, a bem da higidez constitucional, é possível com relação aos princípios restringir, com base no sopesamento de valores constitucionais protegidos, nos casos de colisáo de direitos fundamentais individuais e de terceiros e a outros valores hierarquicamente constitucionais ${ }^{34}$.

O principal aspecto decorrente da restriçáa indiretamente constitucional se refere aos limites dessa restrição pelo legislador ordinário. Se seria declaratório, meramente interpretativo, em face dos princípios colidentes ou se seria dado ao legislador a faculdade de constituir restriçóes para além do ponto diretamente previsto pela carta magna. Concluindo o referido autor, pela impossibilidade de restrição que extrapola aquilo que é admissível em face da ponderação entre os princípios colidentes ${ }^{35}$.

Assim sendo, destacam-se as restriçóes diretamente constitucionais, previstas para o Estado de Defesa e de Sítio, bem como o instituto da requisição administrativa, que encontra guarida, também, no texto constitucional.

\subsection{Conteúdo essencial dos direitos individuais: Limites das restriçôes}

Com relação às limitaçôes municipais, estaduais e federais impostas sobre as liberdades individuais de locomoção e livre iniciativa, tais como as restrições de circulação "toque de recolher" e o fechamento do comércio "lockdownn", tomadas com base no primado da saúde pública, há uma colisão de normas princípios de alta densidade axiológica, próximas do conteúdo essencial da dignidade humana. Havendo risco à centralidade da Constituição, Romeu questiona "se as sucessivas e simultâneas crises levaram à maior aceitação pelos atores políticos das restriçôes e exceçôes constitucionais, num processo de erosão da autoridade moral/axiológica da Constituição" 37 .

Com efeito, deve haver a ponderação em face das demais garantias e liberdade individuais, a fim de se averiguar em concreto a legitimidade da restrição imposta, notadamente em face do direito de propriedade e das liberdades individuais, garantias e direitos prima facie assegurados no atual cenário de crise sanitária.

As teorias sobre o conteúdo essencial, de um lado se diferenciam entre o aspecto de uma situação subjetiva ou objetiva de regulamentaçáo constitucional, de outro lado, as teorias se referem ao caráter absoluto ou relativo dessa garantia. Na doutrina alexyana, a natureza individual dos direitos fundamentais aponta em favor de uma coexistência entre as teorias subjetiva e objetiva ${ }^{38}$.

Para os defensores da teoria relativa, o conteúdo essencial da norma de direito fundamental seria aquilo que resta após o sopesamento dos princípios colidentes. Nessa perspectiva, as restriçôes que estão de acordo com a "máxima" da proporcionalidade, náo violam o conteúdo

34 Ibid., p. 289.

35 Ibid., p. 377.

36 O lockdown é uma expressão em inglês que significa fechamento total ou confinamento.

37 GOMES, Romeu da Cunha. A Constituição em Tempos de Crises e a Pandemia da COVID-19. Direitos e deveres fundamentais em tempos de coronavirus. Org. Saulo José Casali Bahia. São Paulo: Editora Iasp, 2020. p. 234.

38 ALEXY, Robert. Teoria dos direitos fundamentais. Trad. de Virgílio Afonso da Silva. São Paulo: Malheiros, 2008, p. 295-297. 
essencial do direito, nem no caso de nada restar de um dos direitos colidentes em determinado caso concreto ${ }^{39}$.

De acordo com a teoria relativa, o conteúdo essencial é reduzido à máxima da proporcionalidade, diferentemente da teoria absoluta, pela qual todo direito fundamental tem um núcleo, no qual náo seria possível nenhuma intervençáo. Diante disso, conclui Alexy que: "Disso decorre que uma teoria absoluta do conteúdo essencial não pode afirmar que razóes mais importantes não prevalecem, mas apenas que não existem razóes mais importantes" ${ }^{30}$.

Com relação às restrições que vem sendo praticadas pelos entes municipais, estaduais e federais, no atual contexto de crise sanitária, com base no princípio da saúde e da vida, ainda que sem estudos definitivos sobre a eficácia do isolamento social e as repercussóes da crise econômica que sucede tal modelo, devem ser objeto de análise jurídico-constitucional, tanto em relação aos limites dessas ingerências aos direitos fundamentais, quanto em face das competências dos poderes constituídos em realizá-las.

Pois, como destacado, apesar de se tratarem de normas-princípios de alta carga axiológica, ainda assim, deve haver a ponderaçáo em face das demais garantias e liberdade individuais, no intuito de se observar no tempo, caso a caso, a legitimidade e a duração da restrição aplicada, eis que as demais posiçóes de direitos e garantias fundamentais, também o são, apenas, prima facie assegurados, do ponto de vista constitucional, deve-se ter como parâmetro as limitaçóes constitucionalmente previstas para os casos de estado de sítio e de defesa.

\subsection{Custo dos direitos fundamentais (sociais): flexibilização do orçamento público (Covid-19)}

Os direitos fundamentais têm uma relação estreita com os recursos públicos, pois para a sua implementação dependem e se relacionam com as finanças públicas do Estado. Segundo Ricardo Torres, o tributo enquanto forma basilar de derivação da receita do Estado "é o preço da liberdade, preço que o cidadão paga para ver garantido os seus direitos e para se distanciar do Leviatâ" ${ }^{\prime 1}$. Ou seja, a restrição na propriedade privada dos contribuintes, através da tributação, é a forma que o Estado se financia e promove a sua atuação.

Impende destacar que a execução da atividade financeira do Estado Democrático brasileiro se desenvolve através do Poder Executivo, com base no instrumento orçamentário, previamente aprovado pelo Poder Legislativo, constituindo-se, portanto, em uma tarefa de ordem política.

Destaca-se que, os direitos a ações negativas (liberdades individuais) são custosos, na medida em que envolvem o aparelhamento do Estado para garanti-los, a exemplo dos vultuosos custos dispendidos com a segurança pública, acesso à justiça e etc., a fim de promover as liberdades individuais e a garantia do direito de propriedade, notadamente no que diz respeito a sua eficácia horizontal (em relação aos demais particulares).

Assim, os direitos fundamentais, mormente os relacionados à prestação positiva, estão atrelados à saúde financeira do Estado, tendo em vista o custo econômico da promoção desses

39 Ibid., p. 298.

40 Ibid., p. 300.

41 TORRES, Ricardo Lobo. Tratado de Direito Constitucional Financeiro e Tributário: orçamento na Constituição. 3. ed. Rio de Janeiro: Renovar, 2008, v. 5, p. 499. 
Direitos, cabendo ao legislador ordinário a programação orçamentária e a regulamentação da maioria dos direitos sociais, previstos na Carta Magna brasileira, e ao Poder Executivo a tarefa de execução deste orçamento, de acordo com a política promovida.

Em relação à execução das políticas públicas, os direitos à prestação positiva estão adstritos às limitaçóes de ordem econômica, estando limitados à denominada "reserva do possível", expressão doutrinária utilizada para designar as limitaçóes materiais de atuação do Estado. Assim, ante a escassez e a finitude dos recursos públicos, à Administração incumbe a missão de realizar a alocação das receitas, de modo previamente modulado e ponderado pelo legislador, respeitando as disponibilidades orçamentárias do Estado ${ }^{42}$.

Não obstante, o Estado, além das receitas originárias e derivadas, pode se valer do endividamento público, para incrementar a receita, observada a regra de ouro das finanças públicas $^{43}$, expressa no artigo 167 , III da CRFB/88, cuja redação estabelece que o aumento da dívida, por meio de operações de crédito, não deve ultrapassar o volume de despesas de capital, "ressalvadas as autorizadas mediante créditos suplementares ou especiais com finalidade precisa, aprovados pelo Poder Legislativo por maioria absoluta" ${ }^{44}$, complementada pelo disposto no artigo $12, \$ 1^{\circ}$ da Lei Complementar n. 101/2000.

O objetivo da norma é claro, evitar o endividamento para financiar despesas correntes e suas consequências para as geraçóes futuras, promovendo o equilíbrio orçamentário.

No entanto, a regra de ouro não é absoluta, conforme a ressalva constante no próprio texto constitucional do dispositivo retro mencionado, dando espaço para a sua flexibilização nas situaçóes excepcionais, desde que previamente aprovada pelo Poder Legislativo. Ademais, a emenda constitucional $n^{\circ} 106$ de 07 de maio de 2020, no seu art. $2^{\circ}$ prevê transitoriamente que "Será dispensada, durante a integralidade do exercício financeiro em que vigore a calamidade pública nacional de que trata o art. $1^{\circ}$ desta Emenda Constitucional, a observância do inciso III do caput do art. 167 da Constituição Federal”. Sobre a excepcionalidade já advertia Aliomar Baleeiro:

A guerra coloca os governantes em alternativas trágicas. Ou despender, fora e acima das regras da política financeira reputada ótima, ou suportar o desaparecimento da soberania, a ocupação e perda do território [...]. As cifras mais espantosas da dívida pública têm como origem, em todos os países, as atividades bélicas de sua história. Diante dessa contingência inelutável, os escritores abriram exceção para esse tipo de despesa ${ }^{45}$.

Como já mencionado, em 20 de março de 2020 o Congresso Nacional reconheceu por meio de decreto legislativo, para os fins do artigo 65 da Lei Complementar $n^{\circ} 101 / 2000^{46}$,

42 SARLET, Ingo Wolfgang. A Eficácia dos Direitos Fundamentais. 11. ed., Porto Alegre: Livraria do Advogado, 2012, p. 263

43 CARVALHO JUNIOR, Antonio Carlos Costa d'Ávila; GREGGIANIN, Eugênio; MENDES, Graciano Rocha; PEDERIVA, João Henrique; BIJOS, Paulo Roberto Simão. Regra de ouro na Constituição e na LRF: Considerações históricas e doutrinárias. Estudo Técnico Conjunto n. 2/2017. Consultoria de Orçamentos e Fiscalização Financeira (CD) e Consultoria de Orçamentos, Fiscalização e Controle (SF). Brasília: Câmara dos Deputados, 2017, p. 4.

44 BRASIL. Constituição da República Federativa do Brasil, de 1988. Brasília, DF. Disponível em: http://www. planalto.gov.br/ccivil_03/Constituicao/Constituicao.htm. Acesso em: 09 mai, 2020.

45 BALEEIRO, Aliomar. Uma Introdução à Ciência das Finanças. Rio de Janeiro: Forense, 2010, p.600.

46 Art. 65. Na ocorrência de calamidade pública reconhecida pelo Congresso Nacional, no caso da União, ou pelas Assembléias Legislativas, na hipótese dos Estados e Municípios, enquanto perdurar a situação: I - serão suspensas a contagem dos prazos e as disposiçóes estabelecidas nos arts. 23, 31 e 70; II - serấo dispensados 
o estado de calamidade pública. Trata-se de norma autorizativa para a União Federal utilizar recursos no combate à pandemia sem a amarra legal de diversos dispositivos relacionados ao equilíbrio financeiro, flexibilizando, assim, as normas orçamentárias de responsabilidade fiscal.

Notadamente pelas alteraçóes promovidas, em sequência, por meio da Emenda Constitucional n 106 de 07 de maio de 2020 que instituiu "o regime extraordinário fiscal, financeiro e de contrataçóes para enfrentamento de calamidade pública nacional decorrente de pandemia” e das alteraçóes promovidas pela Lei Complementar n 173 de 28 de maio de 2020.

No entanto, antes mesmo da promulgação dos dispositivos acima referidos, em 29 de março de 2020 o Supremo Tribunal Federal, já havia em nítido exemplo de jurisdição constitucional de exceção, decido monocraticamente, em sede liminar na Ação Direta de Inconstitucionalidade $\mathrm{n}^{\circ} 6357$ de Relatoria do Ministro Alexandre de Moraes, pela interpretação conforme à Constituição dos artigos 14, 16, 17 e 24 da Lei de Responsabilidade Fiscal, além do artigo 114 , caput, in fine, e $\$ 14^{\circ}$ da Lei de Diretrizes Orçamentárias do ano de $2020^{47}$.

Além disso, em decisão plenária proferida, ratificou-se a cautelar proferida por unanimidade, em 09 de maio de 2020 nos autos da Ação Direta de Inconstitucionalidade I n ${ }^{\circ}$ 6357, determinou a suspensão cautelar até o julgamento do mérito de mais três dispositivos da Lei Complementar 101/2000, quais sejam o artigo 23, e a íntegra do seu parágrafo segundo, bem como o parágrafo segundo do artigo 12 da Lei de Responsabilidade Fiscal, que contempla a referida regra de ouro das finanças públicas.

Chama atenção o exercício da jurisdição constitucional em tempo de crise, notadamente pelo indicativo de usurpação de competência do Poder Legislativo nas decisóes ora elencadas; mas antes de adentrar no mérito dessa discussão, impende traçar o papel dos Poderes da República, em relação ao exercício das suas funçóes constitucionais relacionadas ao orçamento público e a efetividade dos Direitos Fundamentais, em face da Separação dos Poderes.

Pois, diante da constitucionalização dos direitos fundamentais, e dos amplos poderes de controle desses direitos conferidos ao poder Judiciário, desencadeia-se um problema de competência entre os Poderes Judiciário e Legislativo, extensível à aplicaçáo de todos os direitos fundamentais à açóes positivas. Diante disso, as escolhas decorrentes das despesas públicas passam a ser alvo de controle judicial, e não mais apenas político, (Legislativo e Executivo) ${ }^{48}$.

o atingimento dos resultados fiscais e a limitaçáo de empenho prevista no art. 90. $\$$ 10 $\mathrm{Na}$ ocorrência de calamidade pública reconhecida pelo Congresso Nacional, nos termos de decreto legislativo, em parte ou na integralidade do território nacional e enquanto perdurar a situação, além do previsto nos inciso I e II do caput: (Incluído pela Lei Complementar no 173, de 2020) I - serão dispensados os limites, condiçôes e demais restriçốes aplicáveis à União, aos Estados, ao Distrito Federal e aos Municípios, bem como sua verificação, para: (Incluído pela Lei Complementar $n^{\circ} 173$, de 2020) a) contratação e aditamento de operaçóes de crédito; (Incluído pela Lei Complementar no 173, de 2020) b) concessáo de garantias; (Incluído pela Lei Complementar $n^{\circ} 173$, de 2020) c) contratação entre entes da Federação; e (Incluído pela Lei Complementar no 173, de 2020) d) recebimento de transferências voluntárias; (Incluído pela Lei Complementar $n^{\circ} 173$, de 2020) II - serão dispensados os limites e afastadas as vedaçóes e sançóes previstas e decorrentes dos arts. 35, 37 e 42, bem como será dispensado o cumprimento do disposto no parágrafo único do art. $8^{\circ}$ desta Lei Complementar, desde que os recursos arrecadados sejam destinados ao combate à calamidade pública; (Incluído pela Lei Complementar $\mathrm{n}^{\mathrm{o}}$ 173, de 2020) III - serão afastadas as condiçóes e as vedaçóes previstas nos arts. 14, 16 e 17 desta Lei Complementar, desde que o incentivo ou benefício e a criaçáo ou o aumento da despesa sejam destinados ao combate à calamidade pública. (Incluído pela Lei Complementar no 173, de 2020).

47 BRASIL. Supremo Tribunal Federal. Ação Direta de Inconstitucionalidade. ADI nº 6357/DF. Relator: Min. Alexandre de Moraes. Publicado no DOU de 29 de março de 2020.

48 BARCELLOS, Ana Paula de. A eficácia jurídica dos princípios constitucionais: o princípio da dignidade da pessoa 
Assim sendo, não caberia ao Judiciário se imiscuir na esfera de conformação do legislador, notadamente quanto aos pressupostos e a extensão do conteúdo dos direitos fundamentais sociais. Nesse sentido, a lição de José Carlos de Andrade:

Para que se determinem como direitos, é necessária uma atuação legislativa, que defina o seu conteúdo concreto, fazendo uma opção num quadro de prioridades a que obrigam a escassez dos recursos, o caráter limitado da intervenção do Estado na vida social e, em geral, o próprio princípio democrático. Os preceitos constitucionais respectivos não são, por isso, nesse sentido, aplicáveis imediatamente, muito menos constituem preceitos exequíveis por si mesmos ${ }^{49}$.

Ocorre que, a Constituição brasileira previu a aplicação imediata das normas garantidoras de direitos fundamentais ${ }^{50}$, e, além disso, como fundamento da República Federativa do Brasil, o princípio da dignidade da pessoa humana, bem como, conferiu amplos poderes de atuaçáo e proteção, através do Poder Judiciário, das normas definidoras de direitos fundamentais, inclusive, prevendo açôes específicas, relacionadas à inconstitucionalidade por omissão legislativa, e instrumentos de atendimento à pretensão individual em concreto, através do mandado de injunção, dada a inafastabilidade jurisdição.

Como se observa, há um conflito de competências, entre os Poderes da República, cuja omissão legislativa, muitas vezes deu azo a um ativismo judicial exagerado, de modo que propóe-se buscar uma solução, que possa compatibilizar o problema da efetividade dos direitos fundamentais, respeitando-se a ordem democrática e os espectros de atuação de cada um dos poderes. Principalmente, pela representaçáo indireta do povo através do parlamento e do Executivo (princípio democrático) e de outro lado, o Judiciário não eleito, mas legitimado a salvaguardar os direitos fundamentais pela Constituição, sendo esse um verdadeiro paradoxo dos Estados Democráticos de Direito.

Em lição que pode ser contextualizada, com atual crise econômica decorrente do alastramento da pandemia pelo mundo, já alertava Robert Alexy que a extensão do exercício dos direitos fundamentais sociais aumenta em crises econômicas, por conta que nesse período pode haver pouco a ser distribuído.

Explica o autor alemão que pode parecer plausível a objeção, com relação aos direitos fundamentais sociais definitivos, ainda que mínimos, o que poderia ampliar a crise econômica, pela ausência de flexibilidade orçamentária, e torná-la uma crise constitucional. No entanto, os necessários sopesamentos podem conduzir, em circunstâncias distintas, a direitos definitivos diferentes. Ademais, sustenta o doutrinador que seria exatamente nos tempos de crise que a proteção constitucional, ainda que mínima, de posiçóes sociais parece ser imprescindível ${ }^{51}$.

Ante a limitação econômica, os políticos fazem escolhas orçamentárias para a alocação dos recursos, o que pressupóe preferências, e consequentemente, a judicialização dos direitos

bumana. Rio de Janeiro: Renovar, 2002, p. 92.

49 ANDRADE, José Carlos Vieira de. Os direitos fundamentais na Constituição portuguesa de 1976. Coimbra: Almedina, 1987, p. 207.

50 Art. $5^{\circ}(\ldots)$ : $\$ \mathbf{1}^{\mathbf{0}}$ As normas definidoras dos direitos e garantias fundamentais têm aplicação imediata.

51 ALEXY, Robert. Teoria dos direitos fundamentais. Trad. de Virgílio Afonso da Silva. São Paulo: Malheiros, 2008, p. 510. 
sociais pelos preteridos. A grande questáo levantada na presente pesquisa, se refere a saber se o Poder Judiciário teria competência constitucional e democrática para essa missão ${ }^{52}$.

\subsection{Jurisdição constitucional e a Separação dos Poderes}

No modelo constitucional brasileiro, o espectro de atuação do judiciário vai desde o reconhecimento de uma inconstitucionalidade, podendo fixar prazo para o legislador omisso agir, até a determinação direta do que é obrigatório em virtude da Carta Magna, ante a inafastabilidade de jurisdição. No entanto, a competência do tribunal deve se encerrar nos limites do definitivamente previsto, enquanto o legislador pode ir além desses limites, ainda que não esteja obrigado a fazê-lo ${ }^{53}$.

Como exemplo de direito subjetivo à prestação positiva na Constituição brasileira, temse o artigo $201, \$ 5^{\circ}$, que estabelece o salário mínimo como piso dos benefícios previdenciários, e o Supremo Tribunal Federal - STF, considera uma norma de eficácia vinculante. Além disso, no Brasil, a jurisprudência do STF tem se revelado, nos casos em que a suprema corte reconhece as obrigaçóes sociais de conteúdo mínimo, a exemplo dos medicamentos gratuitos (RE-AgRg 271286/RS, 2000), o acesso à educação infantil de obrigação dos municípios (creches e préescolas), compreendido como o patamar mínimo da educação ${ }^{54}$ (CRFB/88, artigo 208, IV).

O Supremo Tribunal Federal tem entendido que nos casos relacionados à promoção do núcleo mínimo dos direitos sociais, atrelados à vida digna, o Estado sequer pode alegar a indisponibilidade orçamentária, por razóes de prioridades dos gastos públicos.

Neste sentido, trecho da Arguição de Descumprimento de Preceito Fundamental n $45 /$ DF, julgado pelo Ministro Celso de Mello:

(...) comprovada, objetivamente, a incapacidade econômico-financeira da pessoa estatal, desta não se poderá razoavelmente exigir, considerada a limitação material referida, a imediata efetivação do comando fundado no texto da Carta Política". No entanto, apontam que ela "reserva do possível": [...] não pode ser invocada, pelo Estado, com a finalidade de exonerar-se do cumprimento de suas obrigaçóes constitucionais, notadamente quando, dessa conduta governamental negativa, puder resultar nulificação ou, até mesmo, aniquilaçáo de direitos constitucionais impregnados de um sentido de essencial fundamentalidade. [...] não se mostrará lícito ao Poder Público [...] mediante indevida manipulação de sua atividade financeira e/ou político-administrativa, criar obstáculo artificial que revele o ilegítimo, arbitrário e censurável propósito de fraudar, de frustrar e de inviabilizar o estabelecimento e a preservação, em favor da pessoa e dos cidadãos, de condiçôes materiais mínimas de existência ${ }^{55}$.

52 WANG. Daniel Wei Liang. Escassez de recursos, custos dos direitos e reserva do possível na jurisprudência do STF. Revista Direito GV, São Paulo. p. 539-568. jul-dez 2008.

$53 \mathrm{Na}$ jurisprudência do STF, há diversos julgados atrelados acesso à educação (STF, DJ 3 fev. 2006, RE410.715/ SP, Rel. Min. Celso de Mello); a serviços de saúde e medicamentos (STF, DJ 29 abr. 2010, STA 175/CE, Rel. Min. Gilmar Mendes (Presidente)); e com açóes afirmativas em favor de pessoas portadoras de deficiências (STF, DJ 17 out. 2008, ADI 2.649/DF, Rela. Mina . Cármen Lúcia).

54 RE-AgR 410715 e do RE-AgR 436996.

55 BRASIL. Supremo Tribunal Federal. Arguição de Descumprimento de Preceito Fundamental. ADPF 45. Distrito Federal. Relator: Min. Celso de Mello. Publicado no DOU de 29 de abri de 2004. 
Os referidos julgados devem ser analisados com o máximo de cautela, na medida em que a omissão legislativa tem aberto campo para o Judiciário exercer a jurisdição em áreas adstritas a política.

No entanto, também, contextualizando a lição de Luís Roberto Barroso, acerca da atual pandemia, e o conflito entre os princípios que protegem o direito à vida e à saúde entre uns e outros:

Aqui se chega ao ponto crucial do debate. Alguém poderia supor, a um primeiro lance de vista, que se está diante de uma colisão de valores ou de interesses que contrapóe, de um lado, o direito à vida e à saúde e, de outro, a separação de Poderes, os princípios orçamentários e a reserva do possível. A realidade, contudo, é mais dramática. O que está em jogo, na complexa ponderaçấo aqui analisada, e o direito à vida e à saúde de uns versus o direito à vida e à saúde de outros. Não há solução juridicamente fácil nem moralmente simples nessa questáo ${ }^{56}$.

Perfilhando, no entanto, a corrente alexyana, no que toca a ponderação dos valores envolvidos para a possibilidade de intervenção judicial, somente ocorrerá em casos extremos de violação do conteúdo mínimo dos direitos fundamentais, com base na máxima da proporcionalidade (adequação, necessidade e razoabilidade), sempre que não possível assinalar prazo para o Poder competente atuar.

Porém, chama atenção que mesmo nas situaçôes de exceção (Estado de Defesa e Estado de Sítio), conforme visto, o constituinte atribuiu ao Poder Legislativo (Congresso Nacional), a autorização para decretação pelo Executivo da situação transitória excepcional, bem como para autorização da flexibilização orçamentária.

Por conta disso, critica-se a decisão monocraticamente proferida pelo Ministro do Supremo Tribunal Federal (Rel. Alexandre de Moraes), nos autos da ADI n 6.357 de 29 de março de $2020^{57}$, que em sede cautelar, flexibilizou diversas normas já mencionadas, relativa a responsabilidade fiscal para o combate a pandemia, em nítida substituição do Poder constituído legiferante.

A decisão, de questionável caráter, além de violar a cláusula pétrea da separação dos poderes, também atingiu o federalismo, na medida em que retirou dos poderes legislativos estaduais e municipais, a possibilidade de análise de cada ente federado, na medida em que a referida decisão conferiu efeitos para todos os entes da federação que haviam reconhecido o estado de calamidade pública.

Além disso, a mencionada decisão sequer estipulou as medidas de controle orçamentário pelos demais poderes da república, em nítida, e temerária, jurisdição constitucional de exceção.

Em razão isso, que deve prevalecer o constitucionalismo democrático, pois as decisóes judiciais que supostamente devem defender a constituição, podem acabar por fragilizá-la.

No entanto, ainda que posteriormente, com a edição da emenda constitucional $\mathrm{n}^{\circ}$ 106/20, o Congresso Nacional convalidou todos os atos praticados pelo Executivo, compatíveis

56 BARROSO, Luís Roberto. Da falta de efetividade à judicialização excessiva: direito à saúde, fornecimento gratuito de medicamentos e parâmetros para a atuaçáo judicial. 2007. Disponível em: <http://www.lrbarroso. com.br/pt/noticias/medicamentos.pdf>. Acesso em: 08 jun. 2020.

57 BRASIL. Supremo Tribunal Federal. Ação Direta de Inconstitucionalidade. ADI 6357/DF. Relator: Min. Alexandre de Moraes. Publicado no DOU de 29 de março de 2020. 
com a referida emenda, a teor do Art. 10 "Ficam convalidados os atos de gestão praticados a partir de 20 de março de 2020, desde que compatíveis com o teor desta Emenda Constitucional" ${ }^{58}$.

\section{Consideraçóes finais}

Com relação ao Estado de Exceção e aos limites constitucionais das restriçôes aos Direitos Fundamentais, a análise requer sempre uma maior cautela, considerando que não se tratam de situações, verdadeiramente imprevisíveis, pois o próprio constituinte originário traçou as balizas constitucionais do Estado para o enfrentamento desses tipos de graves crises institucionais. No entanto, o constituinte não autorizou qualquer tipo de restrição ou ingerência por parte do Estado, mesmo em tempos de grave crise.

Com relação às restriçôes aos direitos individuais, que vêm sendo praticadas pelos entes municipais, estaduais e federais, no atual contexto de crise sanitária, com base no princípio da saúde e da vida, ainda que sem estudos definitivos sobre a eficácia do isolamento social e as repercussóes da crise econômica que sucede tal modelo, deve haver uma ponderação.

Como visto, apesar de se tratar de normas-princípios de densidade axiológica próxima ao centro do conteúdo da dignidade humana, ainda assim, deve haver uma ponderação em face das demais garantias e liberdade individuais, no intuito de se observar, caso a caso, a legitimidade da restriçáo aplicada, adotando-se como parâmetro principal as limitaçôes constitucionalmente previstas para os casos de estado de exceçáo (Estado de Sítio e Estado de Defesa), tanto em ordem material, quanto formal relacionada a necessidade de ratificação pelo Poder Legislativo, das medidas propostas pelo Executivo.

No que diz respeito aos direitos sociais, os mesmos devem ser atendidos ainda que a situação que autorizou a implementação do estado de exceção tenha repercussão direta na queda orçamentária, pois sem essa proteção, pode-se alastrar ainda mais as consequências da crise institucional.

Para tanto, o próprio constituinte, também, traçou competências arrecadatórias (tributárias) excepcionais, a exemplo do empréstimo compulsório e do imposto extraordinário, bem como a possibilidade do legislativo flexibilizar disposiçôes de ordem orçamentária, conforme consta na própria lei de responsabilidade fiscal.

Assim, em observância ao princípio da separação dos Poderes, a competência de conformação desses direitos seria do legislador ordinário, visto que diretamente legitimado pelo povo, e, por isso, os tribunais só poderiam atuar na matéria após o legislativo tê-la regulamentado.

No contexto de grave crise, deve-se prevalecer o disposto na Constituição, sob pena de instauração de uma jurisdição constitucional de exceção, não sendo o papel do Supremo Tribunal Federal (órgão do judiciário) exercer um poder moderador em relação aos demais Poderes da República.

58 BRASIL. Congresso Nacional, Emenda Constitucional nº 106 de 2020. Brasília, DF. Disponível em: http:// www.planalto.gov.br/ccivil_03/constituicao/emendas/emc/emc106.htm. Acesso em: 09 mai, 2020. 


\section{Referências}

AGAMBEN, Giorgio. Estado de Exceção. Tradução Iraci Poleti. 2 ed. São Paulo: Boitempo, 2004.

ALAN, José Alexandre Zachia. Crise e justiça constitucional - uma tentativa de paralelo entre Portugal e o Brasil e os questionamentos acerca da validade da constituição, in Revista do Ministério Público do RS, Porto Alegre, n. 76, jan-abr/2015, p. 67-85.

ALEXY, Robert. Teoria dos direitos fundamentais. Trad. de Virgílio Afonso da Silva. São Paulo: Malheiros, 2008.

ANDRADE, José Carlos Vieira de. Os direitos fundamentais na Constituição portuguesa de 1976, Coimbra: Almedina, 1987.

BARCELLOS, Ana Paula de. A eficácia jurídica dos princípios constitucionais: o princípio da dignidade da pessoa humana. Rio de Janeiro: Renovar, 2002.

BARROSO, Luís Roberto. Da falta de efetividade à judicialização excessiva: direito à saúde, fornecimento gratuito de medicamentos e parâmetros para a atuação judicial. 2007. Disponível em: <http://www.lrbarroso.com.br/pt/noticias/medicamentos.pdf >. Acesso em: 08 jun. 2020.

BRASIL. Constituição da República Federativa do Brasil, de 1988. Brasília, DF. Disponível em: http://www.planalto.gov.br/ccivil_03/Constituicao/Constituicao.htm. Acesso em: 09 mai, 2020.

BRASIL. Congresso Nacional. Decreto Legislativo no 6, de 20 de março de 2020. Brasília, DF. Disponível em: http://www.planalto.gov.br/ccivil_03/portaria/DLG6-2020.htm. Acesso em: 09 mai, 2020.

BRASIL. Emenda Constitucional nº 106 de 2020. Brasília, DF. Disponível em: http://www. planalto.gov.br/ccivil_03/constituicao/emendas/emc/emc106.htm. Acesso em: 09 mai, 2020.

BRASIL. Lei Complementar Federal n 101/2000. Brasília, DF. Disponível em: http://www. planalto.gov.br/ccivil_03/leis/lcp/lcp101.htm. Acesso em: 09 mai, 2020.

BRASIL. Lei Federal n 13.979/2020. Brasília, DF. Disponível em: http://www.planalto.gov. br/ccivil_03/_ato2019-2022/2020/lei/113979.htm. Acesso em: 09 mai, 2020.

BRASIL. Supremo Tribunal Federal. Ação declaratória de inconstitucionalidade. ADI 6357. Relator: Min. Alexandre de Moraes. Publicado no DOU de 29 de março de 2020. Disponível em: http://www.stf.jus.br/portal/cms/verNoticiaDetalhe.asp?idConteudo=440384. 18 de jun. de 2020 .

BRASIL. Arguição de descumprimento de preceito fundamental. ADPF 45/DF. Relator: Min. Celso de Mello. Publicado no DOU de 04 de maio de 2004.

CARVALHO JUNIOR, Antonio Carlos Costa d'Ávila; GREGGIANIN, Eugênio; MENDES, Graciano Rocha; PEDERIVA, Joáo Henrique; BIJOS, Paulo Roberto Simão. Regra de ouro 
na Constituição e na LRF: Considerações históricas e doutrinárias. Estudo Técnico Conjunto n. 2/2017. Consultoria de Orçamentos e Fiscalização Financeira (CD) e Consultoria de Orçamentos, Fiscalização e Controle (SF). Brasília: Câmara dos Deputados, 2017.

FRIEDRICH, Carl Joachim. Constitutional Government and Democracy. 2. ed. rev. Boston, Ginn, 1950.

MENDES, Gilmar Ferreira; BRANCO, Paulo Gustavo Gonet; Curso de direito constitucional. $7^{\text {a }}$ ed. Sáo Paulo: Saraiva. 2012.

MONIZ, Ana Raquel Gonçalves. Promoção da saúde pública e proteção dos direitos fundamentais: a COVID-19 à luz das repercussốes jurídico-constitucionais e jurídicoadministrativas em Portugal. Cadernos Ibero-Americanos de Direito Sanitário, Brasília, 10(2): abr./jun., 2021, p. 183-210.

GOMES, Romeu da Cunha. A Constituição em Tempos de Crises e a Pandemia da COVID-19. Direitos e deveres fundamentais em tempos de coronavirus. Org. Saulo José Casali Bahia. São Paulo: Editora Iasp, 2020. p. 233-242.

SANTOS. Aricê Moacyr Amaral. O Estado de Emergência. São Paulo: Sugestôes Literárias, 1981.

SARLET, Ingo Wolfgang. A Eficácia dos Direitos Fundamentais. 11. ed., Porto Alegre: Livraria do Advogado, 2012.

SILVA, José Afonso da. Curso de direito constitucional positivo. $-37^{\mathrm{a}}$ ed. rev. e atual. até a Emenda Constitucional n. 76. - São Paulo: Malheiros, 2014.

TORRES, Ricardo Lobo. Tratado de Direito Constitucional Financeiro e Tributário: orçamento na Constituição. 3. ed. Rio de Janeiro: Renovar, 2008, v. 5.

WANG. Daniel Wei Liang. Escassez de recursos, custos dos direitos e reserva do possível na jurisprudência do STF. Revista Direito GV, São Paulo. jul-dez 2008, p. 539-568. 